\title{
A INFLUÊNCIA DA FAMÍLIA NO DESEMPENHO ESCOLAR DOS ESTUDANTES DO ENSINO MÉDIO DE UMA ESCOLA PÚBICA DE CANDIBA - BA
}

\author{
Etevaldo da Silveira Caldas* \\ Valdimir Pereira Reis*
}

\section{RESUMO:}

A presente artigo é resultado de uma pesquisa de mestrado que objetivou analisar a participação dos pais ou responsáveis nas reuniões e eventos realizados no Colégio Estadual Cerqueira Campos, no período de 2016 a 2018, e o reflexo dessa participação no desempenho escolar dos estudantes do Ensino Médio. Sabe-se que o desempenho escolar de estudantes é um assunto que as famílias e os profissionais em educação devem acompanhar, pois é importante compreender se o baixo rendimento dos alunos resultam de fatores dos ambientes nos quais eles estão inseridos. Para tanto utilizamos para subsidiar nossa análise os autores Freitas (2009); Roudinesco (2003); Paro (2000); Danda Prado (1981); Bourdieu (2002). Após as análises dos dados, identificou-se que poucos pais comparecem assiduamente nas reuniões e eventos promovidos pelo colégio, apesar de acharem muito importante a participação nas atividades desenvolvidas pela escola. Quanto ao desempenho acadêmico dos alunos, ficou visível que os maiores rendimentos, em nota, não tem relação com a participação nas reuniões, visto que do total pesquisado identificou-se maior assiduidade de pais/mães com filhos que tem nota abaixo da média enquanto a maioria dos pais/mães com filho acima da média nem sempre estão presentes nas reuniões.

Palavras-chave: Família-escola. Rendimento escolar. Reuniões escolares

\footnotetext{
* Mestrando em Educação pela Facultad Interamericana de Ciencias Sociales. Asunción-PY. E-mail: etevaldocaldas@hotmail.com Telefone: (77) 981201851

* Mestrando em Educação pela Facultad Interamericana de Ciencias Sociales. Asunción-PY. E-mail: valdimir.asa@gmail.com Telefone: (77) 981404513
} 


\section{INTRODUÇÃO}

Este estudo traz uma análise da participação dos pais ou responsáveis nas reuniões e eventos realizados no Colégio Estadual Cerqueira Campos no período de 2016 a 2018 e o reflexo dessa participação no desempenho escolar dos estudantes do Ensino Médio.

A escolha do tema se deu a partir de uma inquietação sobre como a participação da família nas atividades realizadas na escola pode contribuir com a melhoria do processo de aprendizagem dos estudantes do Ensino Médio, haja vista que a maioria das pesquisas que discute essa temática, aborda-a no contexto da Educação Infantil e do Ensino Fundamental, principalmente, nos Anos Iniciais. Sendo assim, o objeto de estudo desta pesquisa é a relação família-escola e sua contribuição para a melhoria da aprendizagem de estudantes do primeiro ano do Ensino Médio, de um Colégio Estadual da Bahia, no período de 2016 a 2018.

Entende-se que a presença da família na escola é de grande relevância, pois pode contribuir significativamente com a formação dos estudantes, com a gestão escolar e com a escola como um todo. Além disso, ao participarem ativamente das atividades realizadas na escola, os pais podem ficar informados sobre o andamento dos trabalhos escolares, podendo melhor acompanhar a atuação dos filhos, seja no que diz respeito à aprendizagem, assim como em relação à conduta deles frente a colegas, professores e funcionários da unidade escolar.

Aqui cabe uma ressalva quanto ao termo acompanhamento escolar, uma vez que é possível encontrar pais totalmente assíduos nas reuniões convocadas pela escola, mas que não acompanham com eficácia os trabalhos extraclasses dos filhos. Ao mesmo tempo é possível encontrar a situação inversa, pouca participação nas reuniões e eficiente acompanhamento em casa.

Neste trabalho, opta-se por investigar a presença dos pais na instituição escolar quando convocados para reuniões e demais eventos. Existe uma preocupação do Colégio Estadual Cerqueira Campos (CECC) em valorizar a presença e a participação das famílias na escola. Uma das estratégias tem sido registrar em uma planilha de acompanhamento a presença dos pais ou responsáveis nas reuniões escolares porque entende que a presença da família amplia os canais de comunicação e que as possibilidades de aprendizagem vão além da sala de aula.

Analisando a relação família-escola compreende-se que a família é a principal parceira nessa relação, pois ela é a instituição responsável pela educação primária do indivíduo - o modo de se alimentar, de se vestir, a higiene, o tratamento para com os outros, as primeiras palavras, 
os primeiros passos e, assim, sucessivamente. Trata-se da base fundamental para o desenvolvimento do indivíduo enquanto ser social. Se o papel da escola é formar o aluno para o exercício da cidadania, inserindo-o no contexto político-social em que se vive, grande parte dessa preparação é feita através da orientação familiar.

Entende-se que a escola é o lugar de consolidar o indivíduo como ser social, capaz de estabelecer relações com outros membros da sociedade e resolver problemas de forma autônoma. Assim, a escola assume um papel político na medida em que procura, intencionalmente, imprimir aos jovens e crianças uma forma de ver e interpretar o mundo. Levando em consideração que uma das funções da escola é preparar o aluno para viver em sociedade, não há como negar a importância em manter uma relação constante entre a instituição de ensino e a família. Além disso, a escola deve estar sempre aberta para receber não apenas os pais, mas também a comunidade na qual o aluno está inserido, pois todos possuem a responsabilidade de participar da formação escolar dos/as estudantes.

Nota-se que o número de pais que frequentam o Colégio Estadual Cerqueira Campos vem diminuindo significativamente a cada ano e há indícios de que esse fator tem influenciado nos rendimentos dos/as estudantes. Dessa forma, este trabalho buscou analisar os estudos já publicados sobre a temática e se apoiou em diferentes teóricos que discutem a contribuição da família para a melhoria do processo de ensino-aprendizagem, a fim de compreender se o acompanhamento familiar tem trazido bons resultados ao rendimento escolar dos estudantes do Colégio mencionado.

Diante do exposto, este trabalho é de grande relevância para o campo científico porque irá ampliar as discussões sobre o tema, principalmente por estudar a temática no Ensino Médio. No que se refere ao campo acadêmico, esta pesquisa poderá servir como base para outros estudos e contribuir com a formação dos futuros docentes, de modo que eles compreendam a importância da participação da família na formação dos estudantes do Ensino Médio.

Além disso, esta pesquisa é de grande relevância social, pois traz informações sobre a relação família-escola e o desempenho dos estudantes do Ensino Médio, sendo que a divulgação de tais dados poderá mobilizar os pais ou responsáveis para uma efetiva participação nas reuniões e eventos realizados pela instituição escolar, a fim de contribuir com a melhoria da aprendizagem dos/as estudantes do Ensino Médio.

\section{RELAÇÃO FAMÍLIA-ESCOLA}


Existe um consenso entre diversos educadores de que um ambiente familiar estruturado a partir da convivência harmoniosa entre pai, mãe e filhos contribui para o bom desempenho escolar do aluno. Quando a relação familiar acontece de modo conflituoso, isso é refletido dentro do ambiente escolar, causando dificuldade de concentração, agressividade, baixa frequência etc.

Freitas (2009), no capítulo “A Instituição do Fracasso", descreve um contexto familiar fragilizado vivido pelo personagem Juninho, gerando como consequência a dificuldade de aprendizagem:

\begin{abstract}
A vida familiar desorganizada definiu muito do que veio a ser a história de Juninho. Sem a confiança no afeto dos pais, ele não pôde adquirir confiança em si mesmo. Sem um ritmo regular de vida doméstica, sem um ambiente seguro e protegido, não poderia haver uma rotina para as lições de casa ou para a dedicação a qualquer outra atividade "espiritual” (...) Sua família nunca foi um lugar de cuidado e proteção, ao contrário, era fonte de medo e insegurança, pois as pessoas mais importantes em sua vida o agrediam constantemente, seja através das pancadas físicas, seja através do descaso e do abandono. (FREITAS, 2009, p. 289).
\end{abstract}

A família é o principal componente do contexto histórico social do aluno, mas sabe-se que a rua, o bairro, a comunidade do entorno à sua casa também contribuem para formação desse contexto. O jeito de se expressar, a linguagem usada, as características socioeconômicas dos moradores cria um perfil de indivíduo que pode se adequar ou não ao modelo de educação escolar ministrado no Brasil.

Se determinado aluno não consegue desenvolver habilidades básicas na sala de aula (leitura, escrita, interpretação), tem baixa frequência e é reprovado por diversas vezes, passa-se uma ideia naturalizada de que esse aluno tem dificuldade de aprendizagem.

Tem sido uma prática costumeira de identificar a causa do baixo rendimento escolar no aluno. Isso acontece tanto no ambiente escolar como fora dele, ou seja, assim como professores, direção e coordenação pedagógica tira a responsabilidade da escola pelo fracasso dos estudantes, os pais também não conseguem enxergar outro motivo que não esteja no próprio aluno.

Freitas (2009) vai mais longe ao dizer que: “[...] antes de enxergarem as causas que determinam as dificuldades dos alunos, os profissionais da instituição escolar só veem os efeitos 
dessas dificuldades, tais como desatenção, desobediência, ausências, indisciplina, desinteresse e agressividade" (FREITAS, 2009, p. 291).

A autora ainda acrescenta que essa atitude acontece por conta do que ela chama de máfé institucional. A escola existe para castigar e punir aqueles que não se adequaram às normas da Instituição, aqueles considerados "maus" alunos. A avaliação é usada como instrumento para classificar os estudantes que demonstraram um bom desempenho escolar e separar aqueles que não se ajustaram à meta estabelecida pela escola.

Assim como Freitas (2009), Paro (2000) em “Qualidade do Ensino: a contribuição dos pais” procura argumentar que a Instituição escolar é a principal responsável pelo fracasso do aluno. É comum ouvirmos professores se queixarem da falta de interesse dessa ou daquela turma, desse ou daquele aluno, desinteresse esse que acaba por levar o aluno à reprovação.

Segundo Paro (2000), esse tipo de postura deve ser combatido no ambiente escolar porque se o aluno está desmotivado a continuar estudando é papel da escola, criar um ambiente propício de aprendizagem. Não se justifica querer encontrar o motivo do fracasso do aluno nele mesmo, a reprovação demonstra que a escola não cumpriu com sua principal função que é de garantir o ensino e a aprendizagem. "Se os alunos não aprendem, a escola não foi produtiva. Dizer que a escola foi produtiva porque deu boa aula, mas o aluno não aprendeu, é o mesmo que dizer que a cirurgia foi um sucesso, mas o paciente morreu” (PARO, 2000, p 14).

Mais preocupante ainda é a tendência naturalizada de atribuir o motivo do fracasso ao aluno. Não somente o professor, o coordenador pedagógico e a direção escolar costuma livrar a escola de qualquer responsabilidade sobre a reprovação de determinado aluno, mas o próprio aluno e/ou a família se colocam como culpados.

O aluno passa a se reconhecer um fracassado porque não se esforçou da forma que deveria, enquanto o corpo pedagógico da escola, visto como alguém com conhecimento técnico fizeram o que deveria ser feito. "É impressionante como a autoridade pedagógica da escola consegue se impor, não deixando ao aluno sequer a perspectiva de se perguntar se acaso não é diferente do que sempre the foi passado, de que ele ou ela é o culpado único por seu fracasso". (PARO, 2000, p 90).

É no seio familiar que o indivíduo adquire a primeira etapa de sua formação enquanto ser humano. Quando atinge a idade escolar ele já tem noções de higiene, de como se alimentar, de se relacionar com outras pessoas, enfim, a família é a base educacional de qualquer pessoa. 
"É na família ainda que a criança recebe orientação e estímulo para ocupar um determinado lugar na sociedade adulta, em função de seu sexo, sua raça, suas crenças religiosas, seu status econômico e social”. (DANDA PRADO, 1981, p 40).

A legislação brasileira reconhece o papel da família na formação educacional, tanto que já aparece no primeiro artigo da Lei de Diretrizes e Bases da Educação Nacional LDB/1996 que "A educação abrange os processos formativos que se desenvolvem na vida familiar, na convivência humana, no trabalho, nas instituições de ensino e pesquisa, nos movimentos sociais e organizações da sociedade civil e nas manifestações culturais." (LDB, 1996, art. $1^{\text {o)}}$ ).

Nota-se que a escola seria apenas um entre os diversos locais onde o indivíduo pode adquirir algum tipo de conhecimento, pois segundo a LDB a educação não é apenas uma formação técnica ou conhecimento especializado para exercer determinada função, mas toda experiência que dê ao sujeito capacidade de viver bem entre as pessoas.

Nesse sentido, a educação adquirida na família, por exemplo, poderá contribuir para a relação social do indivíduo em diversas esferas sociais. Em outras palavras, se a educação está presente em diversos segmentos da sociedade, existe então uma relação de interdependência, de reciprocidade.

Em se tratando da educação escolar, vários autores entendem a família como principal parceira desse processo. Isso porque quando um aluno ingressa numa escola é porque o pai, a mãe ou um responsável fez a matrícula dele e, portanto, responde por qualquer eventualidade que a escola necessitar comunicar a um deles. A família passa ser a primeira interessada no sucesso escolar do aluno. Para que esse sucesso ocorra deve haver uma forte sintonia entre a família e a escola.

(...) a escola que toma como objeto de preocupação levar o aluno a querer aprender precisa ter presente a continuidade entre educação familiar e a escolar, buscando formas de conseguir adesão da família para sua tarefa de desenvolver nos educandos atitudes positivas e duradouras com relação ao aprender e ao estudar. Grande parte do trabalho do professor seria facilitado se o estudante já viesse para a escola predisposto para o estudo e se, em casa, ele tivesse quem, convencido da importância da escolaridade, o estimulasse a esforçar-se ao máximo para aprender. (PARO, 2000, p 16).

Outro ponto debatido por Paro (2000), em relação à educação, é o incentivo dos pais em casa para que o aluno se esforce na escola. Em seus trabalhos de pesquisa identificou que existe sim a preocupação dos pais com a formação escolar do filho. Os pais sabem que é de 
grande importância que o filho adquira uma boa formação escolar, porém nem sempre conseguem acompanhar as atividades em casa ou visitar a escola para saber da situação do filho.

Quando se pergunta aos pais a respeito da continuidade, na escola, da educação dada em casa, as respostas são sempre positivas, enfatizando, inclusive, a escola como a segunda família e a professora como segunda mãe. Todavia, quando nossa atenção se volta para as formas como os pais reagem à realidade da escola, podemos ter conclusão bastante diversa. Embora na escola analisada no estudo de campo se adote uma política de aproximação dos pais aos assuntos da escola, isso não é o que acontece com a generalidade das escolas públicas, em que os usuários são mantidos à distância e sentem medo até mesmo do atendimento que lhes pode ser dedicado quando procuram a secretaria da escola com alguma solicitação. (PARO, 2000, p. 33).

A postura de não acompanhar as tarefas de casa muitas vezes ocorre por falta de conhecimento dos pais sobre o conteúdo, como também, alegam falta de tempo para se dedicar a isso, já que muitos deles quando chegam do trabalho encontra o filho dormindo. Paro (2000) alerta que a responsabilidade de orientar, estimular o aluno a se esforçar nos estudos, é tanto da família como dos professores em sala de aula.

Isso tem sido um problema no enfrentamento das dificuldades apresentadas pelo aluno porque se acredita muito que as responsabilidades de cada um estão definidas e separadas. O professor alimenta a ideia de que sua função exclusiva seja de transmitir uma formação acadêmica, se determinado aluno não se interessa mais pela escola, é com os pais que se deve resolver isso.

Quando se trata do Ensino Médio, essa prática se torna ainda mais visível por se tratar de uma fase em que o aluno já começa a definir o que deseja e não deseja, começa a se sentir independente para definir suas escolhas. Por outro lado, os pais acreditam que ao matricular o filho em uma escola, sua responsabilidade na educação foi transferida para a instituição escolar.

Os professores, muitas vezes, percebem a falta de preparo dos pais para incentivarem os filhos a se esforçarem na escola, por outro lado, se omitem sobre o que fazer. Mesmo nos momentos de discussão sobre a vida escolar dos alunos, o professor acaba por não falar tudo que deveria sobre o aluno, ou prefere não dizer nada, por acreditar que alguma mudança seja impossível de acontecer.

(...) Mesmo aqueles que mais enfaticamente afirmam constatar a falta de um maior preparo dos pais para ajudarem seus filhos em casa se mostram totalmente omissos no tocante à orientação que eles poderiam oferecer, 
especialmente nas reuniões de pais, que é quando há um encontro que se poderia considerar propício para isso. (PARO, 2000, p. 65)

Se os pais ainda se sentem responsáveis pela educação de seu filho, se estão cientes que a escola sozinha não trará a contribuição suficiente para a formação dele, resta então assumir a responsabilidade que lhes compete, procurando sempre manter-se informado com o professor sobre o andamento das atividades escolares.

Porém, um obstáculo apontado por Paro (2000) tem dificultado a boa comunicação entre a família e a escola, trata-se do "medo" que determinados pais sentem pelo atendimento recebido nas escolas públicas. Medo por não se sentirem seguros para conversar com os professores sobre assuntos escolares e, principalmente, medo de só ouvir reclamações sobre o comportamento do filho na escola.

Alguns pais não gostam de frequentar as reuniões da escola porque se sentem inseguros quanto às reclamações que os professores irão fazer do seu filho. Isso porque os professores têm feito das reuniões escolares um "muro de lamentações". Melhorar a comunicação entre os pais e as mães, sabendo explicar a real situação escolar do filho, tecendo elogios dos pontos positivos é uma forma de atrair os pais para o ambiente escolar.

Sobre a participação nas reuniões escolares, os professores costumam reclamar de que os pais daqueles alunos que, normalmente, tem alguma observação quanto à indisciplina, baixa frequência, baixo rendimento e etc., nunca estão presentes, enquanto os pais daqueles que não apresentam essas características estão sempre presentes, buscando informações sobre a vida escolar do filho.

Isso pode ser um indício de que a presença dos pais nas reuniões escolares traz benefícios para a vida acadêmica do aluno, já que os pais que comparecem são aqueles cujos filhos não apresentam nenhuma dificuldade.

Numa visão foucaultiana, a pesquisadora Maria Claudia Dal'Igna (2011) analisa a reunião de pais e mestres além de um simples momento de interação e comunicação entre a escola e os pais de alunos, segundo a autora "a reunião não é apenas uma oportunidade pra aproximar a família da escola, mas também pode ser compreendida como uma técnica de governamento.”(DAL'IGNA, 2011, p.106).

O governamento, segundo ela, são estratégias adotadas pela escola para conhecer a realidade do aluno e da sua família fora da instituição de ensino, e, ao mesmo tempo criar 
mecanismos de controle social sobre os mesmos. A escola moderna precisa transformar a criança e o adolescente em seres 'dóceis'. Para isso precisa 'vigiar' a família como forma de administrar o que DAL'IGNA chama de riscos sociais. Ela usa o depoimento de uma mãe para exemplificar como a instituição escolar se apropria de informações sobre a vida familiar do aluno para poder adotar responsabilidades e decisões:

Para cada professora, [a família] vai ter que explicar tudo de novo; Todo professor faz isso, conversa com cada pai para saber se o seu filho tem algum problema de doença, se pode participar da ginástica, de que religião é. Daí, eles perguntam tudo. Como é que é o relacionamento em casa, como é que ele se relaciona com os colegas, como é que foi o ano que passou (DAL'IGNA, 2011, p. 106).

A LDB, em seu segundo artigo, determina que a educação é "dever da família e do Estado", e, ela visa "o pleno desenvolvimento do educando, seu preparo para o exercício da cidadania e sua qualificação para o trabalho" (BRASIL, 1996, art. 2º). Os autores, portanto, reforça o que a legislação defende sobre o compromisso e obrigação de algumas instituições sobre a educação da criança e do adolescente, nesse caso, o Estado deve oferecer condições para o acesso à escola e a família deve se responsabilizar por manter a formação escolar e humana do filho.

Ainda sobre a obrigação da família para com os filhos, o Código Civil brasileiro, no artigo 1.634, determina que: "Compete a ambos os pais, qualquer que seja a sua situação conjugal, o pleno exercício do poder familiar, que consiste em, quanto aos filhos: I - dirigirlhes a criação e a educação (BRASIL, 2002.)".

A boa relação da escola com os pais e a comunidade do entorno gera um clima de confiança, e, caso o ensino não seja de boa qualidade, pelo menos a escola é uma referência para manter o filho protegido.

Paro (2000), cita um trecho do depoimento da auxiliar de direção da escola, por ele pesquisada, para explicar porque os pais ainda acreditam na escola: "Os pais acreditam, sim, na escola e esse eu acho que é um motivo importante. Não querem que seus filhos fiquem na rua, ele acha que o filho, além de aprender alguma coisa, está resguardado dos perigos da rua e eu concordo com os pais" (PARO, 2000, p. 63). 
Nesse sentido, a escola é vista como uma instituição primordial não apenas na socialização, no comportamento e na formação de valores e princípios da criança mas, também como um lugar de proteção e cuidado.

\section{INSTRUMENTO DE COLETA DE DADOS}

A coleta de dados aconteceu por meio da análise de documentos disponíveis para consulta aberta no Colégio Estadual Cerqueira Campos, a saber: ata de resultados finais, diários de classe e registro da frequência dos pais ou responsáveis nas reuniões e eventos realizados pelo CECC.

Através dessa análise foi possível fazer o levantamento da participação/acompanhamento dos pais ou responsáveis nas atividades realizadas no CECC, no período de 2016 a 2018 e analisar o desempenho escolar dos estudantes no período citado. De acordo com Lüdke e André (1986, p. 38) “a análise documental pode se constituir numa técnica valiosa de abordagem de dados qualitativos, seja complementando as informações obtidas por outras técnicas, seja desvelando aspectos novos de um tema ou problema”.

Além da análise documental, foram aplicados dois questionários semiestruturados, um aos alunos previamente selecionados e autorizados, e, outro aos seus respectivos pais ou responsáveis.

Esse questionário teve por finalidade de coletar mais informações não disponíveis na escola, tais como: escolaridade, profissão, área de atuação dos pais no mercado de trabalho; acompanhamento das atividades extraescolar; opinião dos responsáveis sobre seu envolvimento na vida escolar dos alunos, assim como, a opinião dos estudantes sobre a participação dos seus responsáveis na sua vida escolar.

Segundo Gil (1999, p.128), o questionário pode ser definido "como a técnica de investigação composta por um número mais ou menos elevado de questões apresentadas por escrito às pessoas, tendo por objetivo o conhecimento de opiniões, crenças, sentimentos, interesses, expectativas, situações vivenciadas etc.".

Para analisar a influência da participação da família no desempenho escolar dos estudantes, foi necessário também fazer uma revisão bibliográfica, a fim de entendermos as atuais discussões acerca do tema. $\mathrm{O}$ estudo da literatura se faz necessário para que exista o “domínio de um repertório bibliográfico mais amplo, que permita a criatividade construtiva do 
pesquisador, seja na fundamentação do seu problema, seja na atribuição de significados aos dados" (GATTI, 2012, p. 28).

As fontes de leitura foram adquiridas de várias formas, desde livros, artigos, banco de teses e dissertações da Capes e sites de pesquisa acadêmica (scielo, plataforma família na escola da UFMG, biblioteca virtual, etc.).

Os questionários foram aplicados sem que os sujeitos pudessem ser identificados. Neste contexto, entrevistamos primeiramente o grupo de alunos com rendimento escolar abaixo de seis pontos e seus respectivos pais, e, logo depois o grupo de alunos com média acima de seis pontos e os pais dos mesmos.

A escolha dos alunos com alto e baixo rendimento foi feita pelos diários de classe disponíveis na escola. Para definir se determinado aluno obteve nota superior ou inferior a seis pontos, conforme definido anteriormente, calculou-se a média aritmética a partir da nota final em cada disciplina. No período da coleta de dados, como ainda não havia concluído o ano letivo de 2018, considerou-se as notas da primeira e segunda unidade de seis estudantes da primeira série do Ensino Médio no referido ano letivo.

Outro aspecto a ser considerado é que não houve aqui a intenção de selecionar os sujeitos por sexo, ou seja, a escolha de alunos e alunas se deu aleatoriamente sem seguir o critério de paridade entre sexo masculino e sexo feminino.

Para a análise dos dados foi realizada a Análise de Conteúdo com base em Amado, Costa e Crusóe (2013). De acordo com os referidos autores, a Análise de Conteúdo pode ser uma tática do pesquisador para obter, de modo preciso, uma conclusão a partir da sua capacidade de interpretação sobre determinado objeto. A interpretação de um conteúdo se torna possível quando é 'desmembrado em categorias'.

Desse modo, os dados obtidos através dos questionários e dos documentos disponíveis para consulta aberta no Colégio Estadual Cerqueira Campos foram analisados e interpretados, buscando compreender em que medida a participação dos pais ou responsáveis nas reuniões e nos eventos realizados no Colégio Estadual Cerqueira Campos, em Candiba - BA pode ter contribuído para melhorar o desempenho acadêmico dos estudantes do Ensino Médio, no período de 2016 a 2018.

\section{RESULTADOS E DISCUSSÕES}


Para dialogarmos com os resultados e discussões, apresentamos inicialmente uma descrição do perfil das famílias e dos estudantes que participaram deste estudo, além disso, um resumo do contexto e das condições de vida do conjunto. Logo após, apresentaremos as categorias temáticas identificadas na análise das entrevistas.

\subsection{Descrição do perfil das famílias}

Os resultados revelaram dados que permitiram traçar os perfis das famílias e dos adolescentes participantes da pesquisa. Desse modo, o Quadro I, a seguir, apresenta à identificação fictícia (código) das famílias que participaram o sexo, área residencial, a escolaridade do familiar, profissão e cor, conforme segue abaixo:

Quadro I - Dados sobre os pais/mães de alunos

\begin{tabular}{|l|l|l|l|l|l|}
\hline Sujeitos & Sexo/idade & Residência & Escolarização & Profissão & Cor \\
\hline F1 & Feminino & $\begin{array}{l}\text { Área } \\
\text { urbana }\end{array}$ & $\begin{array}{l}\text { Fundamental } \\
\text { incompleto }\end{array}$ & Lavradora & parda \\
\hline F2 & Feminino & Área rural & $\begin{array}{l}\text { Fundamental } \\
\text { incompleto }\end{array}$ & Doméstica & Parda \\
\hline F3 & Feminino & $\begin{array}{l}\text { Área } \\
\text { urbana }\end{array}$ & $\begin{array}{l}\text { Ensino } \\
\text { Médio } \\
\text { completo }\end{array}$ & Costureira & Parda \\
\hline F4 & Feminino & $\begin{array}{l}\text { Área } \\
\text { urbana }\end{array}$ & $\begin{array}{l}\text { Ensino } \\
\text { Médio } \\
\text { completo }\end{array}$ & Do lar & Negra \\
\hline F5 & Feminino & Área rural & $\begin{array}{l}\text { Ensino } \\
\text { médio } \\
\text { completo }\end{array}$ & Lavradora & Parda \\
\hline F6 & Feminino & Área rural & $\begin{array}{l}\text { Fundamental } \\
\text { incompleto }\end{array}$ & $\begin{array}{l}\text { Merendeira } \\
\text { escolar }\end{array}$ & Parda \\
\hline F5 & Feminino & $\begin{array}{l}\text { Área } \\
\text { urbana }\end{array}$ & $\begin{array}{l}\text { Fundamental } \\
\text { incompleto }\end{array}$ & Lavradora & Parda \\
\hline
\end{tabular}




\begin{tabular}{|l|l|l|l|l|l|}
\hline F9 & Feminino & Área rural & $\begin{array}{l}\text { Fundamental } \\
\text { incompleto }\end{array}$ & Agricultora & Parda \\
\hline F10 & Feminino & $\begin{array}{l}\text { Área } \\
\text { urbana }\end{array}$ & $\begin{array}{l}\text { Ensino } \\
\text { Médio } \\
\text { completo }\end{array}$ & $\begin{array}{l}\text { Dona de } \\
\text { casa }\end{array}$ & Pardo \\
\hline F11 & Masculino & $\begin{array}{l}\text { Área } \\
\text { urbana }\end{array}$ & $\begin{array}{l}\text { Fundamental } \\
\text { incompleto }\end{array}$ & Chaveiro & Pardo \\
\hline
\end{tabular}

A partir da análise dos quadros apresentado, percebe-se que a maioria das famílias residem na área rural e é do sexo feminino, uma grande quantidade são trabalhadoras rurais, além disso, a maior parte dos pais possui o ensino fundamental incompleto e três possuem o ensino médio completo, a maioria se autodeclaram negros (pardos), como apresentado nos gráficos abaixo.

Um fator importante a ser observado nesta investigação é que a maior parte das participantes são mulheres, somente um pai respondeu ao questionário, (como apresentado no gráfico 1), o que fica evidente que a presença de pais (homens) nas reuniões é muito pequena, isso pode ser explicado a partir da teoria defendida por Bourdieu (2002) quando ele discute o domínio exercido pelo homens sobre as mulheres em determinadas situações.

Gráfico 1 - Identificação de gênero

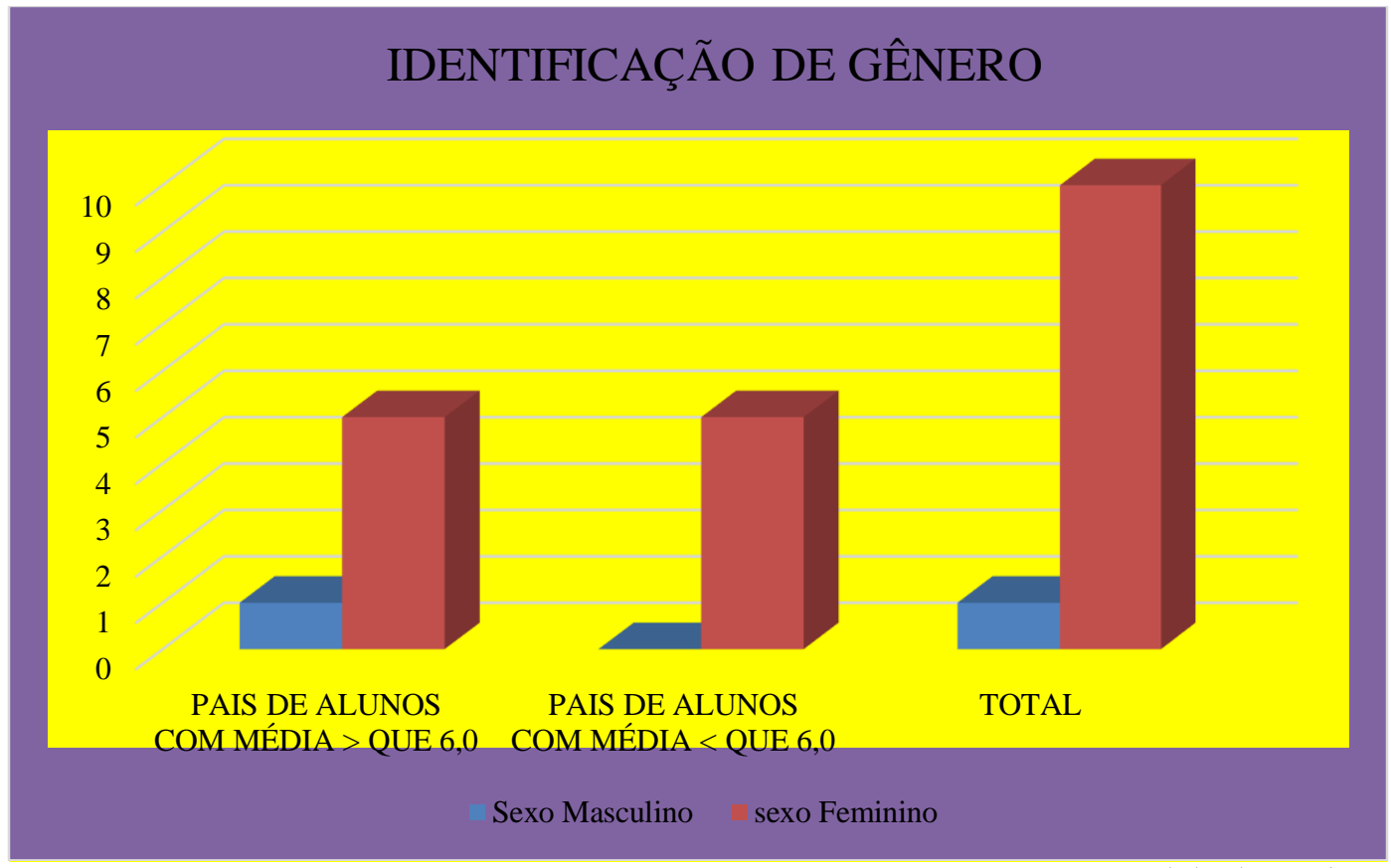

Fonte: dados da pesquisa, 2018 
Em A Dominação Masculina, Bourdieu (2002) salienta que determinadas atividades são reservadas às mulheres porque a sociedade considera como tarefa exclusivamente feminina. Nesta pesquisa, em nenhum momento houve determinação sobre quem dos cônjuges deveria responder as perguntas, a escolha ficou a critério do(a) aluno(a). O predomínio das mães que se dispuseram a responder o questionário não indica, necessariamente, maior poder de decisão sobre a escolarização dos filhos.

O que parece na verdade, é que a função de acompanhar a situação escolar do(a) filho(a) tornou-se uma obrigação ligada à condição da mulher. Atividades que não exigem conhecimento especializado deve deixar ao encargo das mulheres, nesse caso aqui, são as mães que devem matricular o(a) filho(a), participar das reuniões e procurar saber se estar cumprindo com as obrigações escolares. Essa é uma concepção naturalizada e reproduzida na sociedade.

Ainda sobre o papel da mulher, merece destaque também a análise de Roudinesco (2003), quando a autora discute a mudança na concepção de organização familiar por conta da mulher conquistar maior autonomia. Essa autonomia se dá a partir do surgimento da ordem burguesa em que ela passa decidir sobre a gestação por exemplo. Em vista disso, incorporouse na mentalidade da época de que "a mulher deve acima de tudo ser mãe". Neste estudo ficou evidente que na contemporaneidade, a mãe deve acima de tudo acompanhar o filho na escola.

Outra questão observada neste estudo é em relação a escolarização dos pais, percebemos que os alunos filhos de pais com maior grau de escolaridade nem sempre detém maiores notas em relação aos filhos de pais com menor escolaridade.

\section{Gráfico 2 - escolarização dos pais}

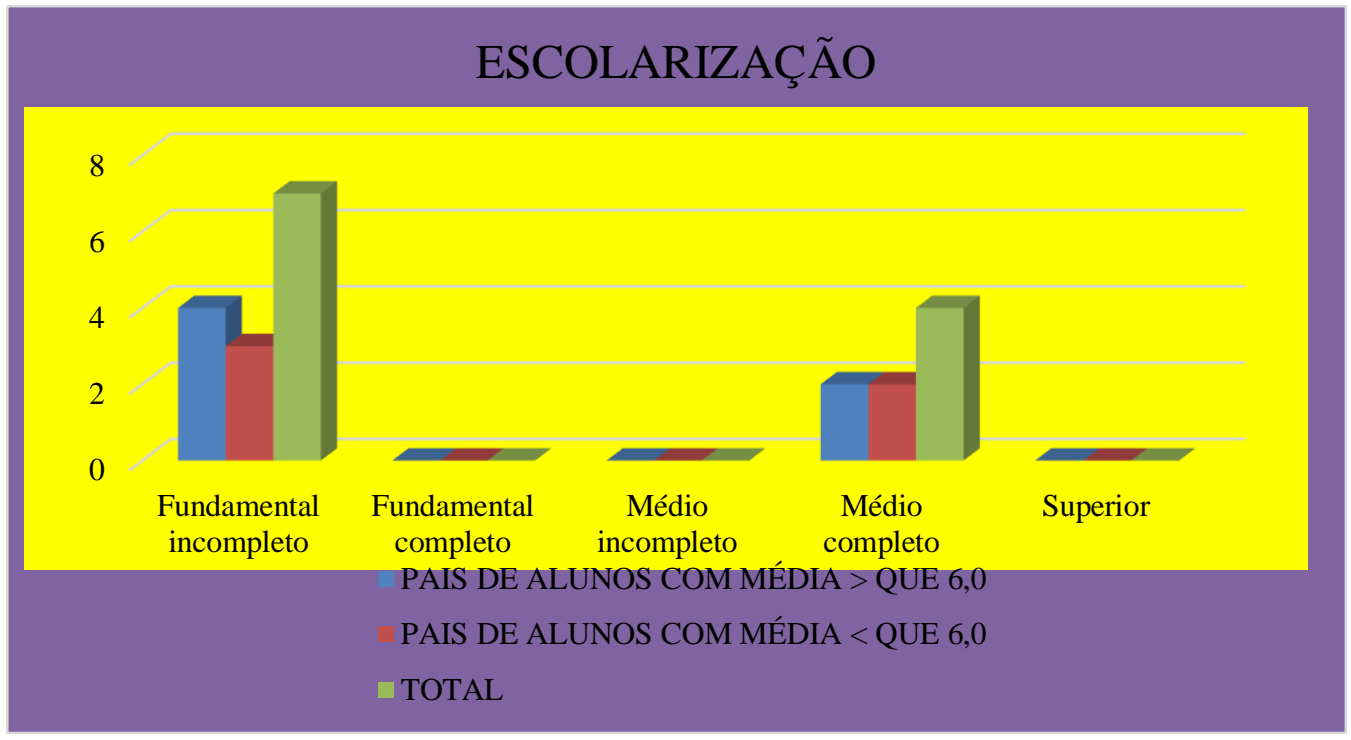


Em outras palavras, pode inferir a pouca relação entre maior escolaridade dos pais e maior rendimento acadêmico dos filhos. Por outro lado, foi possível identificar que o maior número de alunos acima da média são filhos de pais com o Ensino Fundamental incompleto.

A pesquisa evidenciou que para muitos pais, estar presente tem um significado físico, frequentar o espaço escolar, participar das reuniões, eventos e outros compromissos. Para outros, a presença na vida escolar dos filhos significa estabelecer relações com os conteúdos que eles estão aprendendo, ajudar nas tarefas de casa, verificar se realizou as tarefas.

Neste trabalho, compreendemos que ambas as situações constituem participação, contudo, queremos verificar a relação da presença dos pais nas reuniões escolares com as notas dos filhos, assim, percebemos que de todos participantes da pesquisa, somente três pais são participantes ativos das reuniões, sendo que cinco declaram participar algumas vezes e três muito pouco, no entanto, dos três pais que estão sempre presentes nas atividades escolares somente um filho tem nota acima de 6 , enquanto que três alunos, filhos de pais que pouco participam das reuniões têm notas acima de 6 .

Neste sentido fica claro que nem sempre a presença física dos pais na escola contribui para o melhor desenvolvimento dos filhos em relação as notas.

Gráfico 3 - Participação dos pais nas reuniões

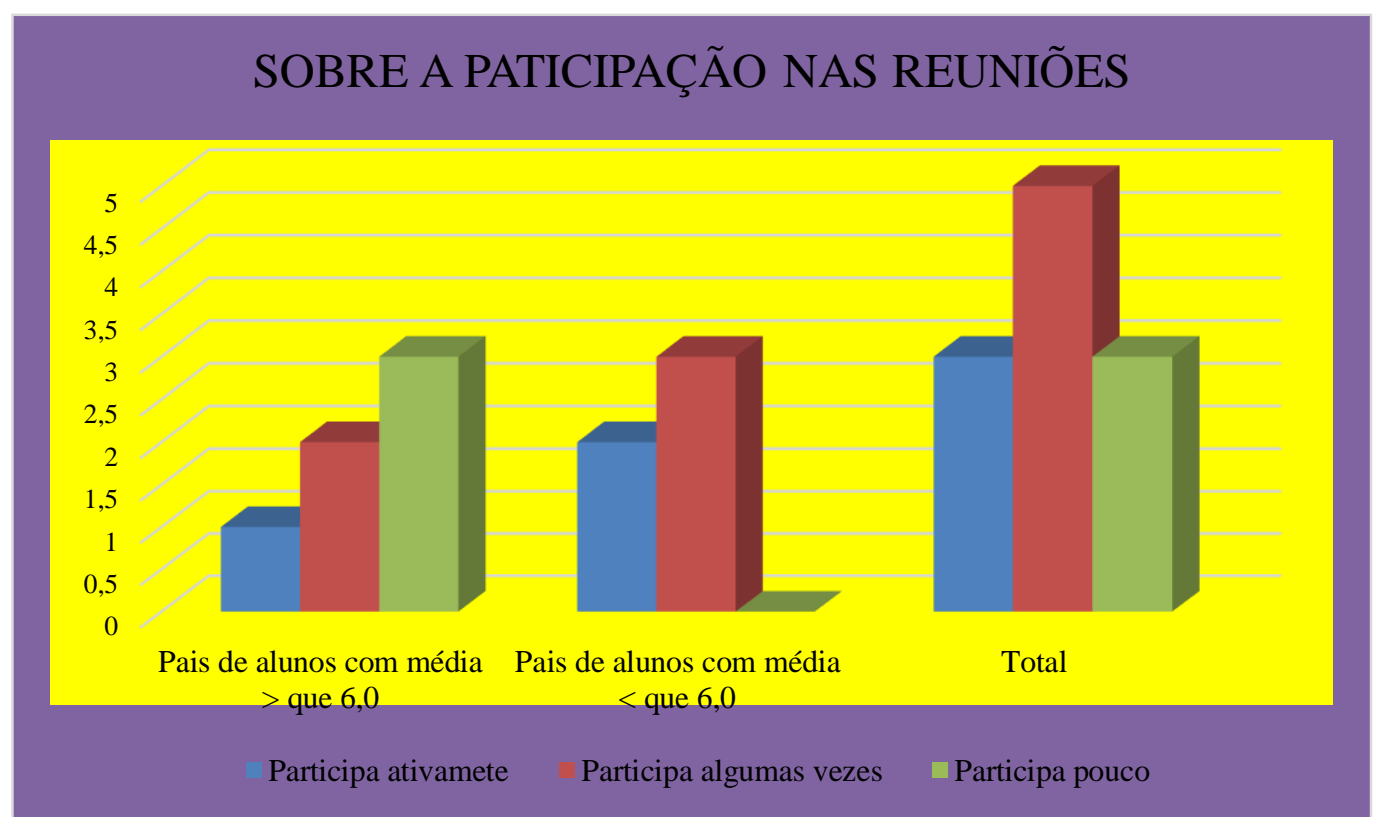


Como apresentado no Gráfico anterior o percentual de pais/mães de alunos, com média acima de 6,0 pontos, que pouco participa das reuniões, corresponde a $50 \%$ dos entrevistados. Isso equivale ao triplo do percentual de pais/mães que declararam participar ativamente 16,6\%. O grupo de pais/mães de alunos com média abaixo de 6,0, declararam participar ativamente ou participa algumas vezes das reuniões, resultando num percentual de $40 \%$ e $60 \%$ respectivamente.

Os dados dos gráficos foram construídos com base nas declarações dos sujeitos, podendo ser passível de inconsistências. A maior participação dos pais/ mães de alunos abaixo da média não pode ser associado à tentativa de omissão, pois os documentos que registram a frequência dos pais nas reuniões do CECC revelam dados semelhantes.

\section{CONCLUSÃO}

A presente pesquisa abordou um estudo que consistiu em analisar a participação dos pais ou responsáveis nas reuniões e eventos realizados no Colégio Estadual Cerqueira Campos, no período de 2016 a 2018, e o reflexo dessa participação no desempenho escolar dos estudantes do Ensino Médio.

Considerando-se as percepções das famílias e alunos, ficou evidente que todos acreditam que a participação dos pais nos eventos escolares é de estrema importância, contudo, a maioria dos pais participantes não comparecem às reuniões, no entanto este não é um fator decisivo para a melhoria das notas dos estudantes, visto que constatou que mesmo com pais participantes ativos das atividades escolares os alunos não possuem notas acima de 6 pontos, o que ficou visível que a relação reunião/desempenho escolar não estão aliados para os alunos da instituição de ensino pesquisada.

Todos concordam que a efetiva participação dos pais na vida escolar dos alunos das séries iniciais do Ensino Fundamental é de suma importância para a melhoria da aprendizagem. O que provavelmente tenha contribuído por apresentar um resultado diferente nesta pesquisa seja o fato de se tratar do Ensino Médio. Neste caso, é possível que outros fatores, como força de vontade do aluno e contexto histórico social vivido por cada estudante, são importantes no processo de aprendizagem.

O aporte teórico ajudou-nos a compreender como o conceito de família vem se constituindo ao longo dos séculos e sua influência na escola e na vida estudantil, além disso 
discutimos a abrangência do termo família e sobre a influência religiosa e o lugar da mulher na família.

No percurso metodológico optou-se por realizar uma pesquisa de natureza qualitativa, tomando como referência os estudos de Minayo (1994). Com base nesse pressuposto, realizamos a interpretação de como a relação família-escola influenciam no desempenho escolar dos/as estudantes a partir do olhar do pesquisador sobre um grupo delimitado de indivíduos, estabelecendo contato direto com os mesmos, observando as relações familiares e o contexto sócio-histórico em que estes vivem, além disso, apresentamos o campo empírico do estudo, com os sujeitos participantes e local da pesquisa.

De acordo com os objetivos propostos no início deste estudo identificou-se que poucos pais comparecem assiduamente nas reuniões e eventos promovidos pelo colégio, apesar de acharem muito importante a participação nas atividades desenvolvidas pela escola. Quanto ao desempenho acadêmico dos alunos, ficou visível que os maiores rendimentos, em nota, não tem relação com a participação nas reuniões, visto que do total pesquisado identificou-se maior assiduidade de pais/mães com filhos que tem nota abaixo da média enquanto a maioria dos pais/mães com filho acima da média nem sempre estão presentes nas reuniões.

Apesar dos indícios da pouca influência da participação dos pais no desempenho acadêmico dos alunos do CECC, não se deve descartar a sua importância na formação da personalidade do adolescente, na construção de suas relações interpessoais dentro e fora do ambiente escolar.

Neste contexto, esperamos que o presente trabalho e análises possam contribuir para ampliar as discussões sobre a temática estudada, sabemos que muito se tem a explorar sobre o assunto a fim de encontrar caminhos para melhoria da evolução dos alunos na escola.

\section{REFERÊNCIAS}

AMADO, J.; COSTA, A. P.; CRUSOÉ, N. A técnica da análise de conteúdo. In: AMADO, J. (Org.). Manual de investigação qualitativa em educação. Coimbra: Imprensa da Universidade de Coimbra, 2013. p. 301-351.

BOURDIEU, Pierre, PASSERON, Jean-Claude. A Reprodução: Elementos para uma teoria do sistema de ensino. Trad. Reynaldo Bairão. $7^{\text {a }}$ ed. Rio de Janeiro: S.A, 1975.

BOURDIEU, Pierre. A dominação Masculina. Tradução Maria Helena Kuhner. $2^{a}$ ed. Rio de Janeiro: Bertrand Brasil, 2002. 
BOURDIEU, Pierre. A escola conservadora: as dificuldades frente à escola e à cultura. In: NOGUEIRA, M. Alice; CATANI, Afrânio (Orgs). Escritos de Educação. $4^{\text {a }}$ edição. Rio de Janeiro. Petrópolis, Vozes, 1998, p. 39-64

BRASIL, Governo do. Código Civil Brasileiro. 2002. Disponível em: http://www.planalto.gov.br/ccivil_03/LEIS/2002. Acesso em 14 de jan. de 2019.

BRASIL, Governo do. Lei de Diretrizes e Bases da Educação Nacional. 1996. Disponível em: http://www.planalto.gov.br/ccivil03/leis/19394.htm. Acesso em 18/01/2019.

DAL'IGNA, Maria Cláudia. Família S/A: um estudo sobre a parceria família-escola. 2011. Disponível em: $<$ https://osfefae.wordpress.com/banco-de-teses/>. Acesso em 02 de ago. de 2017.

FREITAS, Lorena de. A Instituição do Fracasso. In: SOUZA, Jessé (org.). Ralé Brasileira: quem é e como vive. Belo Horizonte: editora UFMG, 2009.p.281-304.

GATTI, Bernardete A. A Construção Metodológica da Pesquisa em Educação: Desafios. Revista Brasileira de Política e Administração da Educação, v. 28, n.1, p. 13-34, jan/abr. 2012.

GIL, Antônio Carlos. Métodos e Técnicas de Pesquisa Social. $6^{\text {a }}$ ed. São Paulo: Atlas, 2008.

LÜDKE, Menga; ANDRÉ, Marli Eliza Dalmazo Afonso de. Pesquisa em Educação: abordagens qualitativas. São Paulo: EPU, 1986.

MINAYO, Maria Cecilia de Souza. (Org.). Pesquisa Social: teoria, método e criatividade. Rio de Janeiro.Petrópolis: Vozes, 1994.

PARO, Vitor Henrique. Qualidade do Ensino: a contribuição dos pais. $1^{\text {a }}$ ed. São Paulo: Xamã, 2000.

PRADO, Danda. O que é Família.10 a ed. Coleção Primeiros Passos. São Paulo: Editora Brasiliense, 1988.

ROUDINESCO, Elisabeth. A Família em Desordem. Rio de Janeiro: Jorge Zahar: 2003 